\title{
Carvacrol Promotes Cisplatin-induced Apoptosis of Triple-negative Breast Cancer Through TRPM7 Channels
}

Jing Li

Qingdao Haici Hospital

Haiyan Ye

Qingdao Haici Hospital

Jun Wang

Qingdao Haici Hospital

Junli Qin

Qingdao Haici Hospital

Lixia Chen ( $\nabla$ lixiachenqdh@163.com )

Qingdao Haici Hospital https://orcid.org/0000-0002-0976-2074

\section{Research Article}

Keywords: Carvacrol, cisplatin, apoptosis, triple-negative breast cancer, TRPM7 channels

Posted Date: March 13th, 2021

DOI: https://doi.org/10.21203/rs.3.rs-291089/v1

License: (c) (1) This work is licensed under a Creative Commons Attribution 4.0 International License. Read Full License 


\section{Abstract}

Triple-negative breast cancer (TNBC) is the most dangerous type of breast cancer. Cisplatin is a chemotherapy agent for solid tumors treatments, but it is subjected to drug resistance. A natural compound, carvacrol, showed anti-cancer potential for TNBC and can be a cisplatin sensitizer. Carvacrol inhibits the transient receptor potential melastatin-like 7 channel (TRPM7), which plays a critical role in cancer apoptosis. In this study, we proposed that carvacrol can promote cisplatin-induced apoptosis of TNBC through TRPM7 channels. We tested this hypothesis using five TNBC cell lines. Cell viability and apoptosis were determined using the MTT and $\mathrm{Bax}$ (Bcl-2-associated X protein) ELISA respectively. 4T1 /BALB/c mice model was used to test the effect of carvacrol on cisplatin treatment. TRPM7 and Bax expression in the tumors were determined using western blotting. We also tested the effect of TRPM7 knockdown and TRPM7 inhibitor, 2-APB, on carvacrol actions in MDA-MB-231. The TRPM7 channel inhibition by carvacrol was confirmed using patch-clamp and Fura-2-based fluorescence quench assay. Results showed that carvacrol enhanced the suppression of cisplatin and cisplatin-induced apoptosis in all five TNBC cancer cell lines. Carvacrol improved cisplatin treatment in mice model by promoting cisplatin-induced apoptosis in tumors, but did not affect TRPM7 in tumors. Both knockdown and 2-APB inhibition of TRPM7 channels eliminated the effects of carvacrol and 2-APB showed a similar effect as carvacrol. Our study demonstrated that carvacrol is a cisplatin sensitizer in TNBC chemotherapy and TRPM7 channels might play a role in the synergistic effect of carvacrol on cisplatin.

\section{Introduction}

Breast cancer is the most common cancer type for females and also the second most common cancer type overall in the world [1]. Every year, breast cancer leads to over 2,000,000 cancer cases and results in over forty thousand clinical deaths [2]. Although breast cancer has been studied extensively and the therapy of this disease has achieved a great improvement, breast cancer is still one of the most dangerous diseases with the highest mortality and the worst prognosis [2]. Thus, further study of breast cancer is required to improve clinical breast cancer therapy.

Surgical treatment is one of the most frequently used therapies for solid breast cancer, but patients with surgical treatment also have a high risk of cancer recurrence and metastasis [3, 4]. Chemotherapies are one of the most effective therapies for breast cancer. Triple-negative breast cancer (TNBC) is the most dangerous subtype of breast cancer because patients with TNBC mostly has undesirable prognosis [5]. TNBC accounts for about $10-20 \%$ of cases among all breast cancer cases [6]. TNBC does not express three key receptors, including (1) the estrogen steroid receptor (ER), (2) progesterone steroid receptor (PR), and (3) tyrosine kinase human epidermal growth factor receptor 2 (HER2) [7]. As TNBC lack known therapeutic receptors, no therapeutic targets are available for an effective TNBC treatment. Only about half of the TNBC cases respond to common chemotherapies [8, 9]. Studies have shown that most conventional chemotherapies for TNBC treatment are subjected to drug resistance during prolonged treatment [10]. 
Cisplatin is one of the most frequently used chemotherapy agents in solid tumors treatments [11]. However, cisplatin is also subjected to the issue of drug resistance [12]. Clinical application of cisplatin is also found to result in many side effects and led to worse life quality for patients [13]. Therefore, it is important to search for proper chemotherapy synergists to enhance therapeutic potency and reduce the side effects of cisplatin. A natural compound, carvacrol, has been found to have anti-cancer properties [14-16]. The clinical combination used of cisplatin plus carvacrol has achieved desirable therapeutic outcomes in some cases in our hospital (data not published).

Studies have shown that carvacrol showed anti-cancer potential for breast cancer $[17,18]$, including some TNBC cell lines [18]. Interestingly, carvacrol was also reported to inhibit the transient receptor potential melastatin-like 7 channel (TRPM7) $[19,20]$. Ion channels have been regarded to be critical in cancer development [21-24]. TRPM7, a divalent cations channel [25], is a member of melastatin-like transient receptor potential (TRPM) subfamilies [26] that are expressed in mammalian tissues [27]. TRPM7 is expressed and plays a role in multiple cancers including breast cancer [28], glioblastoma [20], and ovarian cancer [29]. TRPM7 channels have been found to be critical for apoptosis in cancer [30, 31]. In this preclinical study, we proposed that carvacrol can promote cisplatin-induced apoptosis of triplenegative breast cancer through TRPM7 channels. We hope this study can improve understanding and provide more evidence to support the use of carvacrol as a chemotherapy synergists for cisplatin in clinical TNBC treatments.

\section{Methods And Materials}

\subsection{Reagents}

Carvacrol, cisplatin, MTT Formazan (1-(4,5-Dimethylthiazol-2-yl)-3,5-diphenylformazan), protease inhibitor, and TRPM7 inhibitor 2-Aminoethyl diphenylborinate (2-APB) were was provided by SigmaAldrich (St. Louis, MO, USA). TRPM7 primary antibody (TRPM7 Monoclonal Antibody, S74-25) and RIPA lyse buffer were provided by ThermoFisher Scientific (Waltham, MA, USA). GAPDH primary antibody (AntiGAPDH antibody, ab8245), Bax (Bcl-2-associated X protein) primary antibody (Anti-Bax antibody, ab3191), and all the secondary antibodies were provided by Abcam (Cambridge, UK). The Lipofectamine ${ }^{\circledR} 2000$ kite was obtained from ThermoFisher Scientific (Waltham, MA, USA). Pre-designed TRPM7 siRNAs (4390824) and Silencer ${ }^{\text {TM }}$ Select Negative Control siRNA (4390846) were provided by ThermoFisher Scientific (Waltham, MA, USA). Fura-2-acetoxymethyl ester (Fura-2) was provided by Abcam (Cambridge, UK)

\subsection{Cell lines and cell culture}

Triple-negative breast cancer (TNBC) cell lines MDA-MB-231, MDA-MB-157, MDA-MB-453, BT-20, and MDA-MB-468 were provided by ATCC (Washington, USA). Cells were cultured in DMEM supplied with 10\% FBS (Gibco, ThermoFisher Scientific) using a humidified $5 \% \mathrm{CO}_{2} 37^{\circ} \mathrm{C}$ cell culture incubator.

\subsection{MTT}


Cell viability was determined using the MTT assay, which was used previously [32]. Cells were cultured in the FBS-free medium for $24 \mathrm{~h}$ for starvation before the exposure of testing agents. At the endpoint of the assay, MTT stock solution (12mm) was added to the cells (40 $\mu \mathrm{L} /$ well) for $4 \mathrm{~h}$. Then the OD at $490 \mathrm{~nm}$ was measured.

\subsection{ELISA}

The apoptosis level was measured by testing the Bax level, which was used previously [33]. Human Bax ELISA Kit (ab199080) was provided by Abcam (Cambridge, UK). Briefly, cells were lysed in RIPA lyse buffer with protease inhibitor. $50 \mu \mathrm{L}$ sample was added to the wells, then Antibody Cocktail was added to the wells, followed by the incubation at room temperature for 1 hour. The plate was washed properly and the TMB solution was added to the plate. After $15 \mathrm{~min}$, the stop solution was added to stop the reaction. OD at $450 \mathrm{~nm}$ was measured.

\subsection{Western blotting}

The western blotting assay was used to analyze protein levels in samples, which was described previously [34]. Briefly, samples were lysed in RIPA buffer with protease inhibitor. SDS gel electrophoresis was used to separate the proteins, followed by the transferring of the proteins onto $0.2-\mu$ m polyvinylidene difluoride membranes. The membranes were incubated with $5 \%$ skimmed milk in TBS to block the nonspecific binding. Membranes were then incubated with primary (1:2000 diluted in blocking solution, $4^{\circ} \mathrm{C}$, overnight) and secondary antibodies (1:5000 diluted in blocking solution, RT, 2 h). ECL was used to visualize the proteins on the membranes.

\section{6. siRNA transfection for TRPM7 knockdown}

TRPM7 was knocked down by transfecting siRNA into cells. The transfection method was used previously [35]. Briefly, different concentration of TRPM7 siRNAs was mixed with negative siRNAs accordingly to ensure every transfection transfected $20 \mathrm{nM}$ total siRNA. The siRNAs were transfected to cells using Lipofectamine® 2000. The expression of TRPM7 in cells was analyzed by western blotting assay.

\subsection{Patch-Clamp Recording}

Whole-cell currents were recorded using the patch-clamp recording method, which was described previously [36]. Briefly, the bath solution contained $140 \mathrm{mM} \mathrm{NaCl}, 25 \mathrm{mM}$ HEPES, $1.3 \mathrm{mM} \mathrm{CaCl}$, 1.0 mM $\mathrm{MgCl} 2$, and the $\mathrm{pH}$ was adjusted to 7.3 using $\mathrm{KOH}, 320-335 \mathrm{mOsm}$. The electrode solution contained $140 \mathrm{mM}$ CsF, $7 \mathrm{mM} \mathrm{NaCl}, 10 \mathrm{mM}$ HEPES and $11 \mathrm{mM} \mathrm{EGTA}$, and the pH was adjusted to $7.3 \mathrm{using} \mathrm{CsOH}$, $300 \mathrm{mOsm}$. Capacitance and series resistance was compensated. The voltage was ramped from - 80 to $+80 \mathrm{mV}$ in a second. Currents were normalized to current density by dividing whole-cell capacitance.

\subsection{Fura-2-based fluorescence quench assay}

The TRPM7-mediated $\mathrm{Mn}^{++}$influx was measured with Fura-2-based fluorescence quench assay, which was used previously [37]. Briefly, the tested cells were plated in 96-well plates then loaded with fura-2 
loading-buffer (2 $\mathrm{mM}$ in bath solution used in patch-clamp) for $20 \mathrm{~min}$ at $37 \circ \mathrm{C}$. The plate was washed properly and incubated with tested agents in bath solution for $5 \mathrm{~min} .10 \mathrm{mM} \mathrm{Mn}{ }^{++}$solution was added and the fluorescence (excitation $360 \mathrm{~nm} /$ emission $510 \mathrm{~nm}$ ) of fura-2 was measured.

\subsection{Orthotopic murine breast cancer models}

The orthotopic murine breast cancer model was used to mimic the development and therapy of breast cancer. The model was used in many other studies [38-40]. Briefly, 4T1 cells were injected in the mammary fat pad of female BALB/c mice to induce breast cancer. The mice were evenly allocated to four groups according to their body weight. 4 groups $(n=8)$ were injected intraperitoneally with the vehicle, 3 $\mathrm{mg} / \mathrm{kg}$ cisplatin, $200 \mathrm{mg} / \mathrm{kg}$ carvacrol, and $3 \mathrm{mg} / \mathrm{kg}$ cisplatin $+200 \mathrm{mg} / \mathrm{kg}$ carvacrol respectively. The animals were fed until the death of the animals and the survival data of all animals was recorded. In another set of animal experiment, 4T1 cells were injected in the mammary fat pad of female mice and the mice were allocated to four groups according to their body weight. 4 groups were injected intraperitoneally with vehicle $(n=6), 3 \mathrm{mg} / \mathrm{kg}$ cisplatin $(n=7), 200 \mathrm{mg} / \mathrm{kg}$ carvacrol $(n=6)$, and $3 \mathrm{mg} / \mathrm{kg}$ cisplatin $+200 \mathrm{mg} / \mathrm{kg}$ carvacrol $(n=8)$ respectively. The body weight and tumor volume were measured every three days. All the animals were euthanized at the endpoint of the experiment (day 21) and the net tumor weight was determined. The tumors were collected for western blotting assay. Data of animals that died before the endpoint of the experiment were excluded.

\subsection{Statistical analysis}

Data are presented as means \pm SEM. Student's t-test or one-way analysis was used to analyzed significance. A P-value of 0.05 or lower was considered significant.

\section{Results}

\subsection{IC50 of carvacrol and cisplatin inhibition toward viability of TNBC cell lines.}

To determined a proper concentration for this study, we firstly measured the $\mathrm{IC}_{50}$ of carvacrol and cisplatin inhibition toward viability of five TNBC cell lines we used in this study. Cell viability was determined using a common viability assay, MTT assay [41]. After 48 hours exposure, the $\mathrm{IC}_{50}$ of carvacrol for all five TNBC cell lines ranged from $193-166 \mu \mathrm{M}$. MDA-MB-231 had the highest $\mathrm{IC}_{50}$ and BT-20 had the lowest $\mathrm{IC}_{50}$ (Fig. 1A-E). A previous study reported that carvacrol at 50-500 $\mu \mathrm{M}$ significantly inhibited the viability of multiple breast cancer cell lines and the $\mathrm{IC}_{50}$ was about $500 \mu \mathrm{M}$ which was consisted with our results. To be mentioned, the $\mathrm{IC}_{50}$ of TRPM7 suppression by carvacrol was reported to be $83 \mu \mathrm{M}$ [42]. We used carvacrol at $100 \mu \mathrm{M}$ in the subsequent study because this concentration only slightly inhibited viability and it is enough to inhibit considerable amount of TRPM7 currents according to the previous study [42]. In addition, the $\mathrm{IC}_{50}$ of cisplatin for all five TNBC cell lines were between 43.75 to $56.05 \mu \mathrm{M}$. MDA-MB-468 had the lowest $\mathrm{IC}_{50}$ and MDA-MB-453 had the highest $\mathrm{IC}_{50}$ (Fig. 1F-J). A previous 
study showed that $\mathrm{IC}_{50}$ of cisplatin inhibiting breast cancer cells was about $50-30 \mu \mathrm{M}$ [43] which was consisted with our results. In this study, we used $40 \mu \mathrm{M}$ cisplatin in the subsequent study.

\subsection{Carvacrol promoted cisplatin-induced cell viability suppression in TNBC cell lines}

We tested whether carvacrol affected cisplatin-induced cell viability suppression in TNBC cell lines. For the control, cisplatin at $5 \mu \mathrm{M}$ significantly inhibited the viability of all TNBC cancer cell lines. Compared to cisplatin alone, all cell lines treated with $5 \mu \mathrm{M}$ cisplatin plus $100 \mu \mathrm{M}$ carvacrol dramatically reduced the cell viability (Fig. 2A-E). This indicated that carvacrol dramatically facilitates the suppression of cisplatin toward cell viability.

\subsection{Carvacrol promoted cisplatin-induced cell apoptosis in TNBC cell lines}

Since carvacrol dramatically increased the suppression of cisplatin toward cell viability, we proposed that the effect was mediated by cisplatin-induced apoptosis, thus we used ELISA to test the apoptosis biomarker Bax level. For the control, cisplatin at $5 \mu \mathrm{M}$ significantly induced the apoptosis of all TNBC cancer cell lines. Compared to cisplatin alone, all cell lines treated with $5 \mu \mathrm{M}$ cisplatin plus $100 \mu \mathrm{M}$ carvacrol dramatically increased the cell apoptosis (Fig. 2F-J). This indicated that carvacrol dramatically facilitates the apoptosis induction of cisplatin toward TNBC cells. We suggested that the effect of carvacrol on cisplatin might be mediated by apoptosis induction of cisplatin.

\subsection{Carvacrol promoted cisplatin-mediated survival improvement of an orthotopic murine breast cancer model.}

To further explore the feasibility of carvacrol as a chemotherapy synergist for cisplatin, we tested our hypothesis in an orthotopic murine breast cancer model (Fig. 3A). Firstly, we determined the effect of cisplatin plus carvacrol treatment on animal survival. Results showed that cisplatin significantly improved the survival of breast cancer-bearing animals, while carvacrol further enhanced the effect of cisplatin (Fig. 3B).

\subsection{Carvacrol improved cisplatin-mediated suppression of breast cancer development in an orthotopic murine breast cancer model.}

In this study, we also focused on the effect of the treatment on the tumor size and body weight. We did another set of animal experiments using the same model and observed the change of tumor size and body weight of the animals survived at day 21 (Fig. 4A). Results showed that cisplatin treatment dramatically decreased the bodyweight of the animals, while cisplatin plus carvacrol treatment only cause a slight reduction in body weight (Fig. 4B). The treatment of cisplatin also significantly suppressed the tumor growth as indicated by the tumor size and tumor volume, while cisplatin plus carvacrol 
treatment further decreased the growth of the tumor (Fig. 4C-E). These results indicated that the carvacrol might improve life quality and facilitated the suppression of cisplatin toward breast tumors.

\subsection{Carvacrol improved cisplatin-induced apoptosis of breast cancer in an orthotopic murine breast cancer model.}

In the in vitro study, we had demonstrated that carvacrol promoted cisplatin-induced cell apoptosis in TNBC cell lines. Here we also analyzed the Bax level in tumor samples to determine the apoptosis of breast cancer cells in tumor tissues. Results showed that cisplatin significantly increased the Bax expression while the cisplatin plus carvacrol further increased Bax expression in tumors (Fig. 4FH). These results demonstrated that carvacrol promoted cisplatin-induced tumor apoptosis in an orthotopic murine breast cancer model.

\subsection{TRPM7 mediated current regulation is a potential mechanism for apoptosis regulation of carvacrol.}

A previous study has shown that TRPM7 mediated currents were critical for breast cancer cell viability [28]. In this study, we hypothesis that TRPM7 mediated current regulation is a mechanism for carvacrol actions. We analyzed the TRPM7 expression in tumor samples we collected in the animal study. Results showed that the treatment did not affect TRPM7 expression (Fig. 4FG). Hence, we suggested the effect of carvacrol was not mediated by the regulation of TRPM7 expression, but might be mediated by the regulation of TRPM7 currents suppression.

\subsection{TRPM7 knockdown in MDA-MB-231.}

To further tested whether the TRPM7 plays a role in the enhancement effect of carvacrol on cisplatin suppression, we transfected siRNA to silence TRPM7 expression in MDA-MB-231. The siRNA concentration-dependently reduced TRPM7 level. $0.5,1,2,4,10$, and $20 \mathrm{nM}$ siRNA reduced TRPM7 by $4 \%$, $52 \%, 64 \%, 88 \%, 94 \%$, and $99 \%$ respectively (Fig. 5AB). Thus, we used $20 \mathrm{nM}$ siRNA in the subsequent study because this concentration almost completely silenced TRPM7 expression.

\subsection{TRPM7 knockdown eliminated the effects of carvacrol}

After the TRPM7 knockdown, the carvacrol failed to affect the viability of MDA-MB-231 and also failed to promote the suppression of cisplatin toward MDA-MB-231 viability (Fig. 5C). In terms of apoptosis, after the TRPM7 knockdown, the carvacrol failed to affect the apoptosis of MDA-MB-231 and also failed to increase cisplatin-induced apoptosis in MDA-MB-231 (Fig. 5D). These results indicated that TRPM7 was involved in the actions of carvacrol.

\subsection{The inhibition of carvacrol on TRPM7 channels.}

The knockdown experiment demonstrated that TRPM7 was involved in carvacrol actions, however, at this point we were not certain whether the effect was mediated by TRPM7 channels or the kinase domain of TRPM7. Therefore, we determined to used a TRPM7 inhibitor, 2-APB, to block the channels. The TRPM7 channel function was determined using both patch-clamp recording and Fura-2-based quench assay. The 
patch-clamp recording measured the outward rectification as TRPM7-like currents. Results showed that 2APB at $200 \mu \mathrm{M}$ reduced TRPM7-like currents in MDA-MB-231 by $75 \%$ while carvacrol at $100 \mu \mathrm{M}$ reduced TRPM7-like currents in MDA-MB-231 by 40\% (Fig. 6AB). The Fura-2AM-based quench assay measured the $\mathrm{Mn}^{++}$influx mostly mediated by TRPM7. Results showed that 2-APB at $200 \mu \mathrm{M}$ reduced TRPM7 mediated $\mathrm{Mn}^{++}$influx in MDA-MB-231 by $80 \%$ while carvacrol at $100 \mu \mathrm{M}$ reduced TRPM7 mediated $\mathrm{Mn}^{++}$ influx by $50 \%$ (Fig. 5EF). These results confirmed that the TRPM7 was significantly inhibited by both 2APB and carvacrol respectively.

\subsection{TRPM7 inhibitor 2-APB eliminated the effect of carvacrol}

We repeated the experiment with $2002-\mathrm{APb}$. With 2-APB, the carvacrol failed to affect the viability of MDA-MB-231 and also failed to promote the suppression of cisplatin toward MDA-MB-231 viability (Fig. 6E). In terms of apoptosis, with 2-APB, the carvacrol failed to affect the apoptosis of MDA-MB-231 and also failed to increase cisplatin-induced apoptosis in MDA-MB-231 (Fig. 6F). These results indicated that the effects of carvacrol were mediated by TRPM7 channels.

\subsection{TRPM7 inhibitor 2-APB showed a similar effect as carvacrol.}

As we proposed carvacrol promoted the potency of cisplatin through TRPM7 channels, the blocking of TRPM7 channels by other agents should also promote the potency of cisplatin as carvacrol. As a result, we expected that 2-APB had a similar role as carvacrol. Results verified our hypothesis. Compared to cisplatin alone, 2-APB significantly decreased the viability and also increased apoptosis of MDA-MB-231. This further confirmed that TRPM7 channel function is involved in cisplatin-induced apoptosis in MDAMB-231.

\section{Discussion}

Undesirable drug resistance and side effects limit the clinical application of cisplatin in TNBC patients. In our hospital, the clinical application of cisplatin combined with traditional medicine containing carvacrol resulted in favorable outcomes in some TNBC patients. The combination treatment of cisplatin plus carvacrol has shown promising therapeutic potential for TNBC. The main purpose of this study was to collected preclinical evidence to support the application of this combination treatment in clinical TNBC patients. As carvacrol can inhibit the TRPM7 channels [19, 20], we also identified TRPM7 channels as the pharmacological target involved in carvacrol action.

Although the application of cisplatin alone has resulted in significant inhibition toward cancer both in vivo and in vitro, a clinical trial has shown that it had no significant therapeutic effect in TNBC patients 
[44]. The drug resistance of cisplatin might account for the insignificant in the clinical trial. Besides, cisplatin treatment also resulted in side effects such as peripheral neuropathy [45], brain damage, and cognitive impairment [46]. In our hospital, we often apply cisplatin with the prescription of traditional medicine according to patients' conditions. Many traditional medicines are used in cancer treatments [47]. A great number of studies have revealed that some compounds from traditional medicine can be useful for the therapy of many diseases [48-53]. Thus, traditional medicine is a good source for the discovery of proper synergists for cisplatin. Carvacrol was identified as one of such promising candidates.

In this study, we conducted both in vitro and in vivo studies to test the enhancing effect of carvacrol on cisplatin. We expected that carvacrol can increase the inhibition of cisplatin toward TNBC cells. We tested this hypothesis in five TNBC cell lines including MDA-MB-231, MDA-MB-157, MDA-MB-453, BT-20, and MDA-MB-468. In all five TNBC cell lines tested, carvacrol significantly enhanced the viability suppression of cisplatin. Cisplatin inhibits cancers by damaging DNA double-strand [54]. Many studies also showed that cisplatin induces apoptosis of cancer cells by multiple pathways [55-57]. We proposed that the carvacrol action is associated with its effect on apoptosis, thus we test the apoptosis factor Bax protein level in these cell lines. We found that carvacrol promoted the cisplatin-induced apoptosis of TNBC cells.

We also tested the effect of carvacrol on cisplatin treatment in an animal model. Results showed that the application of carvacrol enhanced the potency of cisplatin. Compare to the group with cisplatin alone, the tumor volume in the group with cisplatin plus carvacrol treatment was significantly lower. In addition, body weight loss results from the decrease in food intake are always concerns for clinical cisplatin treatment [58]. The bodyweight of animals in the group with cisplatin plus carvacrol treatment did not decrease as that in the group with cisplatin treatment. Thus, we suggested animals in the group with cisplatin plus carvacrol group might have a better life quality. We also determined the Bax level in tumor samples to test our hypothesis in apoptosis. Results showed that the group with cisplatin plus carvacrol showed a higher apoptosis level than that in the group with cisplatin alone. This demonstrated that carvacrol improved the cisplatin-induced apoptosis in the tumor.

Because carvacrol was first known as a non-specific inhibitor for TRPM7 [19, 20], we proposed that TRPM7 might be involved in the pharmacological action of carvacrol. We determined TRPM7 expression in tumor samples and did not found any significant difference in TRPM7 expression. We suggested that carvacrol would not affect the expression of TRPM7 but would regulate breast cancer by its inhibition toward TRPM7 channels. We conducted a silencing experiment to test this hypothesis. TRPM7 was knocked down in MDA-MB-231. Results showed that the knockdown of TRPM7 eliminated the enhancing effect of carvacrol, indicating that TRPM7 is an essential target on the carvacrol pharmacological pathway. However, the knockdown of TRPM7 not only removed the TRPM7 channel but also remove the kinase domain of TRPM7. The elimination might result in the removal of the kinase domain rather than the inhibition of the channels. Although the function of the kinase domain of TRPM7 is still largely unknown, it was supposed to play a critical role in cells [25]. To further confirm the TRPM7 channels made a difference in this action, we used a TRPM7 inhibitor, 2-APB. Results showed that blocking of 
TRPM7 by 2-APB also eliminated the effect of carvacrol, and 2-APB showed a similar effect on cisplatin suppression. These results demonstrated that TRPM7 channels are involved in the enhancing effect of carvacrol on cisplatin. However, this study had several limitations. Firstly, 2-APB is not specific to TRPM7, we can not rule out its effect on other channels; secondly, although we confirmed that TRPM7 channel function was critical in this process, we are not sure whether the kinase domain also play any roles in this process; thirdly, the exact regulatory pathway conecting TRPM7 and apoptosis is still unclear.

The major clinical treatment for solide breast tumors was surgery which might involved anesthetics. Recent studies has shown that anesthetics might affect breat cancer treatments. Insterestingly, a local anesthetics lidocaine has been found to inhibited TRPM7 [59]. Therefore, the understanding of carvacrol's pharmacological actions on TRPM7 might optimized the use of carvacrol as a chemotherapy synergist for cisplatin.

The main conclusion of this study was that carvacrol has promising potential as a cisplatin sensitizer in TNBC chemotherapy and that TRPM7 channels might play a critical role in the synergistic effect of carvacrol on cisplatin.

\section{Declarations}

\section{Ethics approval}

The animal study was consented by the Ethics Committee of Qingdao Hiser hospital.

\section{Consent for publication}

All author had given consent for publication of this paper.

\section{Availability of data and materials}

The data that support the findings of this study are available from the corresponding author upon reasonable request.

\section{Competing interests}

There is no conflict of interest.

\section{Funding}

This study was supported by the Qingdao Hospital of Traditional Chinese Medicine.

\section{Authors' contributions}

Jing Li had made substantial contributions to conception and design, or acquisition of data, or analysis and interpretation of data. Haiyan Ye, Jun Wang, Junli Qin, and Lixia Chen Been had been involved in drafting the manuscript or revising it critically for important intellectual content. 
Acknowledgments

We thank the support of the Qingdao Hospital of Traditional Chinese Medicine.

\section{References}

1. Siegel RL, Miller KD, Jemal A (2019) Cancer statistics, 2019. CA: a cancer journal for clinicians 69 (1):7-34

2. DeSantis CE, Ma J, Gaudet MM, Newman LA, Miller KD, Goding Sauer A, Jemal A, Siegel RL (2019) Breast cancer statistics, 2019. CA: a cancer journal for clinicians 69 (6):438-451

3. Li R, Liu H, Dilger JP, Lin J (2018) Effect of Propofol on breast Cancer cell, the immune system, and patient outcome. BMC anesthesiology 18 (1):77. doi:10.1186/s12871-018-0543-3

4. Liu H (2020) A clinical mini-review: Clinical use of Local anesthetics in cancer surgeries. The Gazette of Medical Sciences 1 (3):030-034

5. Chaudhary LN, Wilkinson KH, Kong A (2018) Triple-Negative Breast Cancer: Who Should Receive Neoadjuvant Chemotherapy? Surgical oncology clinics of North America 27 (1):141-153. doi:10.1016/j.soc.2017.08.004

6. Sporikova Z, Koudelakova V, Trojanec R, Hajduch M (2018) Genetic Markers in Triple-Negative Breast Cancer. Clinical breast cancer 18 (5):e841-e850. doi:10.1016/j.clbc.2018.07.023

7. Kumar P, Aggarwal R (2016) An overview of triple-negative breast cancer. Archives of gynecology and obstetrics 293 (2):247-269. doi:10.1007/s00404-015-3859-y

8. Xu H, Eirew P, Mullaly SC, Aparicio S (2014) The omics of triple-negative breast cancers. Clinical chemistry 60 (1):122-133. doi:10.1373/clinchem.2013.207167

9. Hurley J, Reis IM, Rodgers SE, Gomez-Fernandez C, Wright J, Leone JP, Larrieu R, Pegram MD (2013) The use of neoadjuvant platinum-based chemotherapy in locally advanced breast cancer that is triple negative: retrospective analysis of 144 patients. Breast Cancer Res Treat 138 (3):783-794. doi:10.1007/s10549-013-2497-y

10. Isakoff SJ (2010) Triple-negative breast cancer: role of specific chemotherapy agents. Cancer journal (Sudbury, Mass) 16 (1):53-61. doi:10.1097/PPO.0b013e3181d24ff7

11. Dickson MA, Carvajal RD, Merrill AH, Jr., Gonen M, Cane LM, Schwartz GK (2011) A phase I clinical trial of safingol in combination with cisplatin in advanced solid tumors. Clinical cancer research : an official journal of the American Association for Cancer Research 17 (8):2484-2492. doi:10.1158/1078-0432.ccr-10-2323

12. Amable $L$ (2016) Cisplatin resistance and opportunities for precision medicine. Pharmacol Res 106:27-36. doi:10.1016/j.phrs.2016.01.001

13. Cooley ME, Davis L, Abrahm J (1994) Cisplatin: a clinical review. Part II-Nursing assessment and management of side effects of cisplatin. Cancer nursing 17 (4):283-293 
14. Potočnjak I, Gobin I, Domitrović R (2018) Carvacrol induces cytotoxicity in human cervical cancer cells but causes cisplatin resistance: Involvement of MEK-ERK activation. Phytotherapy research : PTR 32 (6):1090-1097. doi:10.1002/ptr.6048

15. Luo Y, Wu JY, Lu MH, Shi Z, Na N, Di JM (2016) Carvacrol Alleviates Prostate Cancer Cell Proliferation, Migration, and Invasion through Regulation of PI3K/Akt and MAPK Signaling Pathways. Oxidative medicine and cellular longevity 2016:1469693. doi:10.1155/2016/1469693

16. Khan F, Singh VK, Saeed M, Kausar MA, Ansari IA (2019) Carvacrol Induced Program Cell Death and Cell Cycle Arrest in Androgen-Independent Human Prostate Cancer Cells via Inhibition of Notch Signaling. Anti-cancer agents in medicinal chemistry 19 (13):1588-1608. doi:10.2174/1871520619666190731152942

17. Mari A, Mani G, Nagabhishek SN, Balaraman G, Subramanian N, Mirza FB, Sundaram J, Thiruvengadam D (2020) Carvacrol Promotes Cell Cycle Arrest and Apoptosis through PI3K/AKT Signaling Pathway in MCF-7 Breast Cancer Cells. Chinese journal of integrative medicine. doi:10.1007/s11655-020-3193-5

18. Arunasree KM (2010) Anti-proliferative effects of carvacrol on a human metastatic breast cancer cell line, MDA-MB 231. Phytomedicine : international journal of phytotherapy and phytopharmacology 17 (8-9):581-588. doi:10.1016/j.phymed.2009.12.008

19. Parnas M, Peters M, Dadon D, Lev S, Vertkin I, Slutsky I, Minke B (2009) Carvacrol is a novel inhibitor of Drosophila TRPL and mammalian TRPM7 channels. Cell calcium 45 (3):300-309

20. Chen W-L, Barszczyk A, Turlova E, Deurloo M, Liu B, Yang BB, Rutka JT, Feng Z-P, Sun H-S (2015) Inhibition of TRPM7 by carvacrol suppresses glioblastoma cell proliferation, migration and invasion. Oncotarget 6 (18):16321

21. Liu H (2020) Nav channels in cancers: Nonclassical roles. Global Journal of Cancer Therapy 6 (1):5. doi:https://dx.doi.org/10.17352/gjct

22. Prevarskaya N, Skryma R, Shuba Y (2018) Ion Channels in Cancer: Are Cancer Hallmarks Oncochannelopathies? Physiol Rev 98 (2):559-621. doi:10.1152/physrev.00044.2016

23. Liu H (2020) A prospective for the role of two-pore channels in breast cancer cells. Global Journal of Cancer Therapy 6 (1):001-003. doi:10.17352/2581-5407.000026

24. Liu H (2020) A Prospective for the Potential Effect of Local Anesthetics on Stem-Like Cells in Colon Cancer. Biomedical Journal of Scientific \& Technical Research 25 (2):18927-18930

25. W Runnels L (2011) TRPM6 and TRPM7: A Mul-TRP-PLIK-cation of channel functions. Current pharmaceutical biotechnology 12 (1):42-53

26. Zou ZG, Rios FJ, Montezano AC, Touyz RM (2019) TRPM7, Magnesium, and Signaling. International journal of molecular sciences 20 (8). doi:10.3390/ijms20081877

27. Runnels LW, Yue L, Clapham DE (2001) TRP-PLIK, a bifunctional protein with kinase and ion channel activities. Science 291 (5506):1043-1047

28. Liu H, Dilger JP, Lin J (2020) The Role of Transient Receptor Potential Melastatin 7 (TRPM7) in Cell Viability: A Potential Target to Suppress Breast Cancer Cell Cycle. Cancers 12 (1). 
doi:10.3390/cancers12010131

29. Wang J, Liao Q-j, Zhang Y, Zhou H, Luo C-h, Tang J, Wang Y, Tang Y, Zhao M, Zhao X-h (2014) TRPM7 is required for ovarian cancer cell growth, migration and invasion. Biochemical and biophysical research communications 454 (4):547-553

30. Huang Y, Leng TD, Inoue K, Yang T, Liu M, Horgen FD, Fleig A, Li J, Xiong ZG (2018) TRPM7 channels play a role in high glucose-induced endoplasmic reticulum stress and neuronal cell apoptosis. The Journal of biological chemistry 293 (37):14393-14406. doi:10.1074/jbc.RA117.001032

31. Cao R, Meng Z, Liu T, Wang G, Qian G, Cao T, Guan X, Dan H, Xiao Y, Wang X (2016) Decreased TRPM7 inhibits activities and induces apoptosis of bladder cancer cells via ERK1/2 pathway. Oncotarget 7 (45):72941-72960. doi:10.18632/oncotarget.12146

32. Li R, Xiao C, Liu H, Huang Y, Dilger JP, Lin J (2018) Effects of local anesthetics on breast cancer cell viability and migration. BMC cancer 18 (1):666

33. Nacif-Pimenta R, da Silva Orfanó A, Mosley IA, Karinshak SE, Ishida K, Mann VH, Coelho PMZ, da Costa JMC, Hsieh MH, Brindley PJ, Rinaldi G (2019) Differential responses of epithelial cells from urinary and biliary tract to eggs of Schistosoma haematobium and S. mansoni. Sci Rep 9 (1):10731. doi:10.1038/s41598-019-46917-y

34. Liu X, Liu H, Xiong Y, Yang L, Wang C, Zhang R, Zhu X (2018) Postmenopausal osteoporosis is associated with the regulation of SP, CGRP, VIP, and NPY. Biomedicine \& pharmacotherapy = Biomedecine \& pharmacotherapie 104:742-750. doi:10.1016/j.biopha.2018.04.044

35. Li X, Peng B, Zhu X, Wang P, Xiong Y, Liu H, Sun K, Wang H, Ou L, Wu Z, Liu X, He H, Mo S, Peng X, Tian Y, Zhang R, Yang $L$ (2017) Changes in related circular RNAs following ERbeta knockdown and the relationship to rBMSC osteogenesis. Biochemical and biophysical research communications 493 (1):100-107. doi:10.1016/j.bbrc.2017.09.068

36. Inoue H, Murayama T, Tashiro M, Sakurai T, Konishi M (2014) Mg(2+)- and ATP-dependent inhibition of transient receptor potential melastatin 7 by oxidative stress. Free radical biology \& medicine 72:257-266. doi:10.1016/j.freeradbiomed.2014.04.015

37. Zierler S, Yao G, Zhang Z, Kuo WC, Pörzgen P, Penner R, Horgen FD, Fleig A (2011) Waixenicin A inhibits cell proliferation through magnesium-dependent block of transient receptor potential melastatin 7 (TRPM7) channels. Journal of Biological Chemistry 286 (45):39328-39335

38. Safavi A, Kefayat A, Ghahremani F, Mahdevar E, Moshtaghian J (2019) Immunization using male germ cells and gametes as rich sources of cancer/testis antigens for inhibition of 4T1 breast tumors' growth and metastasis in BALB/c mice. International immunopharmacology 74:105719. doi:10.1016/j.intimp.2019.105719

39. Bagheri SM, Abdian-Asl A, Moghadam MT, Yadegari M, Mirjalili A, Zare-Mohazabieh F, Momeni H (2017) Antitumor effect of Ferula assa foetida oleo gum resin against breast cancer induced by 4T1 cells in BALB/c mice. Journal of Ayurveda and integrative medicine 8 (3):152-158. doi:10.1016/j.jaim.2017.02.013 
40. Li R, Huang Y, Liu H, Dilger JP, Lin J (2018) Comparing volatile and intravenous anesthetics in a mouse model of breast cancer metastasis.

41. Liu H, Dilger JP, Lin J (2020) Effects of local anesthetics on cancer cells. Pharmacology \& Therapeutics 212:107558. doi:10.1016/j.pharmthera.2020.107558

42. Li L, He L, Wu Y, Zhang Y (2020) Carvacrol affects breast cancer cells through TRPM7 mediated cell cycle regulation. Life sciences 266:118894. doi:10.1016/j.Ifs.2020.118894

43. Gambini V, Tilio M, Maina EW, Andreani C, Bartolacci C, Wang J, lezzi M, Ferraro S, Ramadori AT, Simon OC, Pucciarelli S, Wu G, Dou QP, Marchini C, Galassi R, Amici A (2018) In vitro and in vivo studies of gold(I) azolate/phosphane complexes for the treatment of basal like breast cancer. European journal of medicinal chemistry 155:418-427. doi:10.1016/j.ejmech.2018.06.002

44. Chalakur-Ramireddy NKR, Pakala SB (2018) Combined drug therapeutic strategies for the effective treatment of Triple Negative Breast Cancer. Bioscience reports 38 (1). doi:10.1042/bsr20171357

45. Mao-Ying QL, Kavelaars A, Krukowski K, Huo XJ, Zhou W, Price TJ, Cleeland C, Heijnen CJ (2014) The anti-diabetic drug metformin protects against chemotherapy-induced peripheral neuropathy in a mouse model. PLoS One 9 (6):e100701. doi:10.1371/journal.pone.0100701

46. Zhou W, Kavelaars A, Heijnen CJ (2016) Metformin Prevents Cisplatin-Induced Cognitive Impairment and Brain Damage in Mice. PLoS One 11 (3):e0151890. doi:10.1371/journal.pone.0151890

47. Liu H (2020) Effect of Traditional Medicine on Clinical Cancer. Biomedical Journal of Scientific \& Technical Research 30 (4):23548-23551

48. Liu H, Xiong Y, Wang H, Yang L, Wang C, Liu X, Wu Z, Li X, Ou L, Zhang R, Zhu X (2018) Effects of water extract from epimedium on neuropeptide signaling in an ovariectomized osteoporosis rat model. Journal of ethnopharmacology 221:126-136. doi:10.1016/j.jep.2018.04.035

49. Liu H, Xiong Y, Zhu X, Gao H, Yin S, Wang J, Chen G, Wang C, Xiang L, Wang P, Fang J, Zhang R, Yang $L$ (2017) Icariin improves osteoporosis, inhibits the expression of PPARgamma, C/EBPalpha, FABP4 mRNA, N1ICD and jagged1 proteins, and increases Notch2 mRNA in ovariectomized rats. Experimental and therapeutic medicine 13 (4):1360-1368. doi:10.3892/etm.2017.4128

50. Wu Z, Ou L, Wang C, Yang L, Wang P, Liu H, Xiong Y, Sun K, Zhang R, Zhu X (2017) Icaritin induces MC3T3-E1 subclone14 cell differentiation through estrogen receptor-mediated ERK1/2 and p38 signaling activation. Biomedicine \& pharmacotherapy = Biomedecine \& pharmacotherapie 94:1-9. doi:10.1016/j.biopha.2017.07.071

51. Chen G, Wang C, Wang J, Yin S, Gao H, Xiang LU, Liu H, Xiong Y, Wang P, Zhu X, Yang LI, Zhang R (2016) Antiosteoporotic effect of icariin in ovariectomized rats is mediated via the Wnt/beta-catenin pathway. Experimental and therapeutic medicine 12 (1):279-287. doi:10.3892/etm.2016.3333

52. Haixia W, Shu M, Li Y, Panpan W, Kehuan S, Yingquan X, Hengrui L, Xiaoguang L, Zhidi W, Ling 0 (2020) Effectiveness associated with different therapies for senile osteopo-rosis: a network Metaanalysis. J Tradit Chin Med 40 (1):17-27

53. Wang C, Chen G, Wang J, Liu H, Xiong Y, Wang P, Yang L, Zhu X, Zhang R (2016) Effect of Herba Epimedium Extract on Bone Mineral Density and Microstructure in Ovariectomised Rat. Journal of 
Pharmaceutical and Biomedical Sciences 6 (5)

54. Kanno S, Hyodo M, Suzuki K, Ohkido M (1985) Effect of DNA-damaging agents on DNA replication and cell-cycle progression of cultured mouse mammary carcinoma cells. Japanese journal of cancer research : Gann 76 (4):289-296

55. Li X, Chen W, Jin Y, Xue R, Su J, Mu Z, Li J, Jiang S (2019) miR-142-5p enhances cisplatin-induced apoptosis in ovarian cancer cells by targeting multiple anti-apoptotic genes. Biochemical pharmacology 161:98-112. doi:10.1016/j.bcp.2019.01.009

56. Morovati A, Ahmadian S, Jafary H (2019) Cytotoxic effects and apoptosis induction of cisplatinloaded iron oxide nanoparticles modified with chitosan in human breast cancer cells. Molecular biology reports 46 (5):5033-5039. doi:10.1007/s11033-019-04954-w

57. Kim HR, Lee GS, Kim MS, Ryu DG, So HS, Moon HC, Lee YR, Yang SH, Kwon KB (2018) Effects of Banxia Xiexin Decoction () on Cisplatin-Induced Apoptosis of Human A549 Lung Cancer Cells. Chinese journal of integrative medicine 24 (6):436-441. doi:10.1007/s11655-017-2922-x

58. Garcia JM, Scherer T, Chen JA, Guillory B, Nassif A, Papusha V, Smiechowska J, Asnicar M, Buettner C, Smith RG (2013) Inhibition of cisplatin-induced lipid catabolism and weight loss by ghrelin in male mice. Endocrinology 154 (9):3118-3129. doi:10.1210/en.2013-1179

59. Liu H, Dilger JP, Lin J (2021) Lidocaine Suppresses Viability and Migration of Human Breast Cancer Cells: TRPM7 as A Target for Some Breast Cancer Cell Lines. Cancers 13 (2):234. doi:10.3390/cancers 13020234

\section{Figures}


(A)

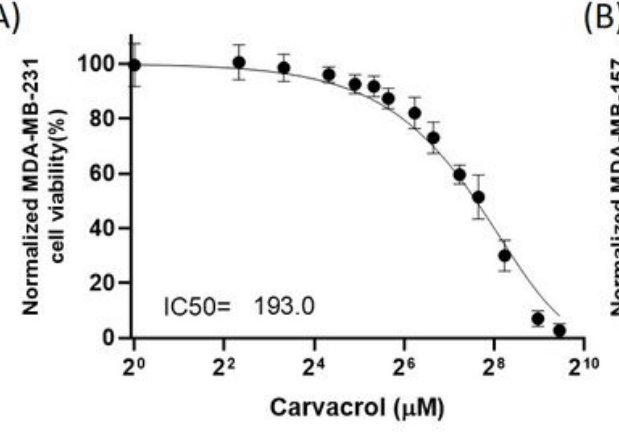

(B)

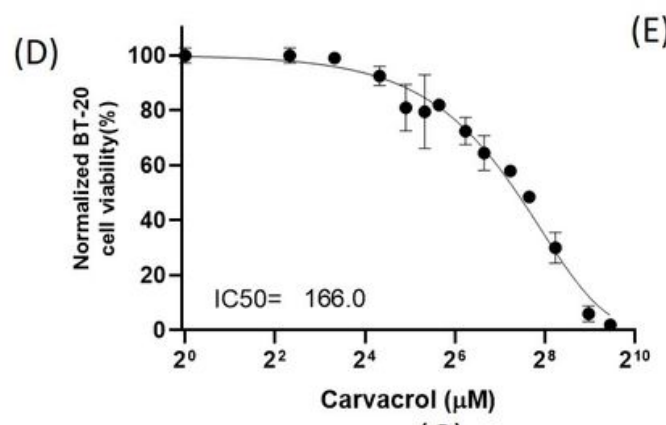

(F)

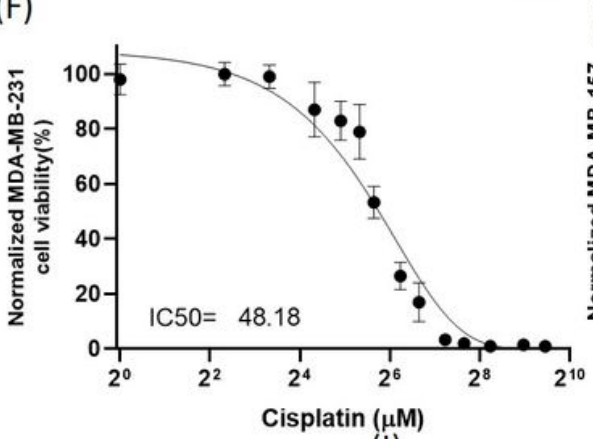

(I)

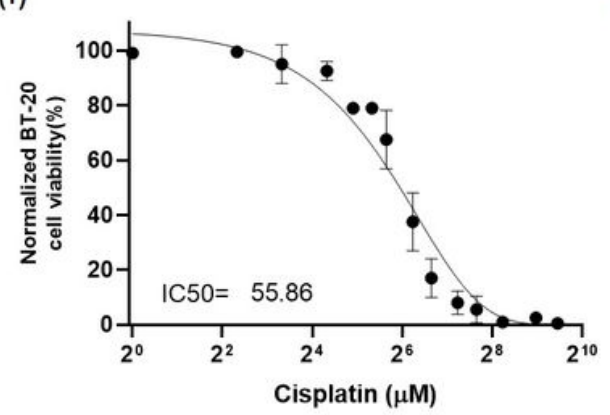

(E)
(C)
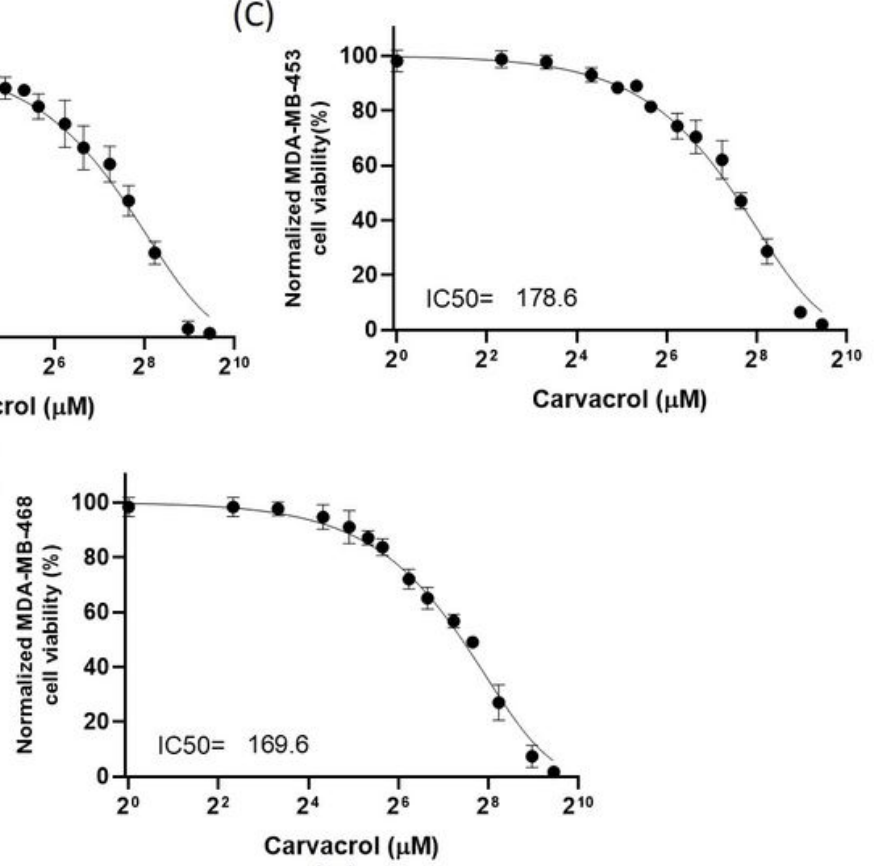

(H)
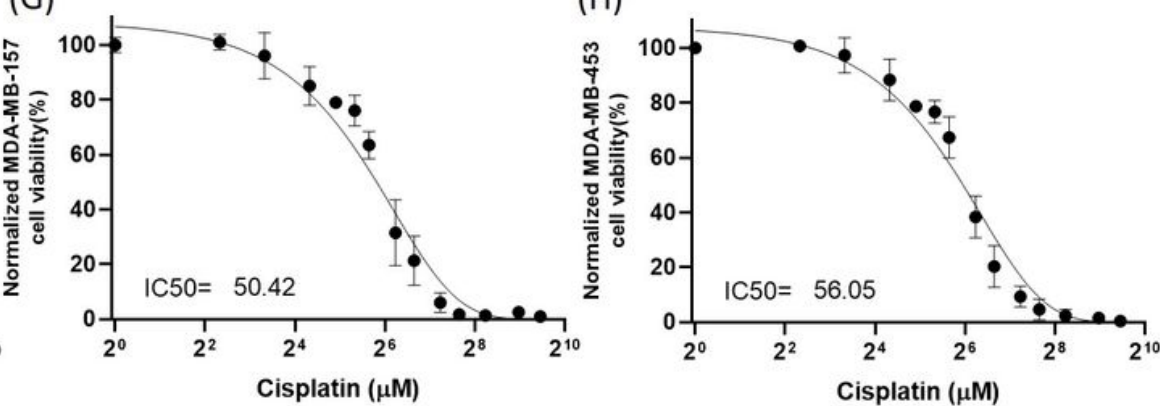

(J)

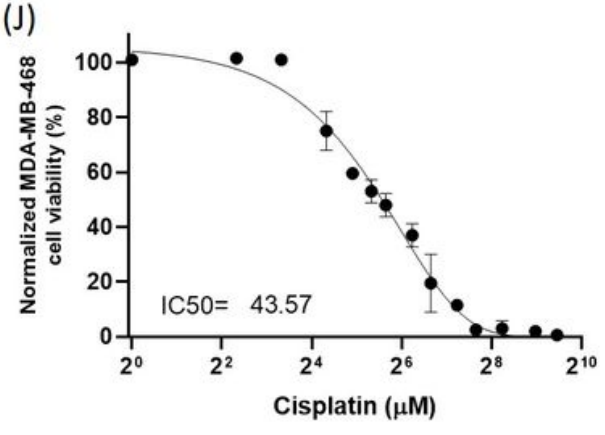

Figure 1

IC50 of Carvacrol and cisplatin inhibition toward viability of TNBC cell lines. The cells were exposed to tested drugs for 48 hours and the viability was determined using MTT assay. The IC50 was analyzed and presented in the figures. 
(A)

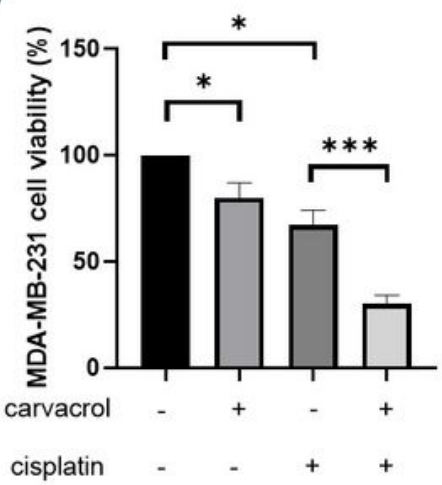

(D)

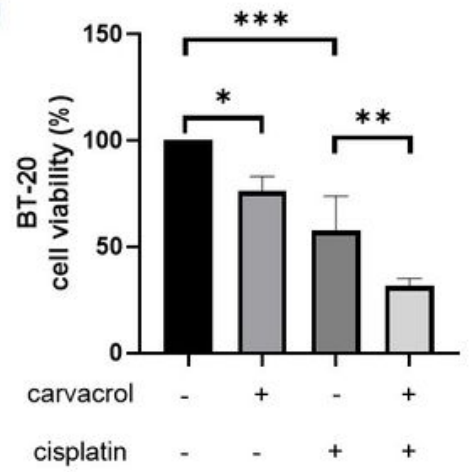

(F)

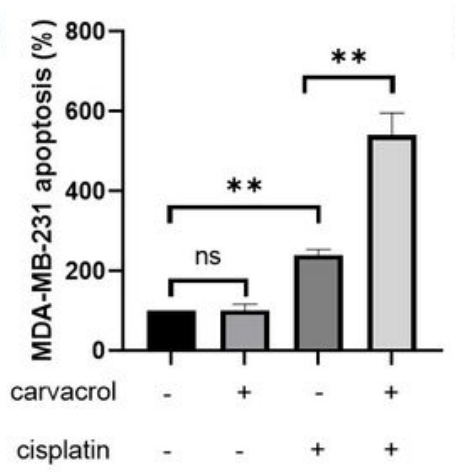

(I)

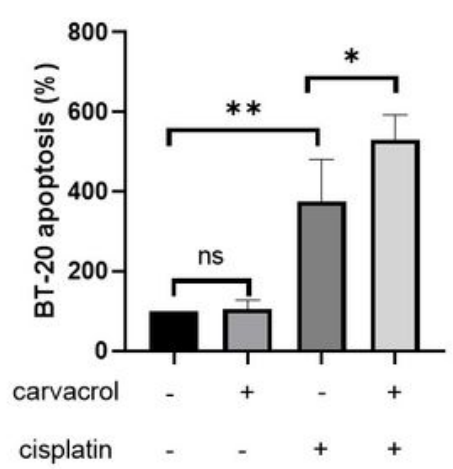

(G)
(B)

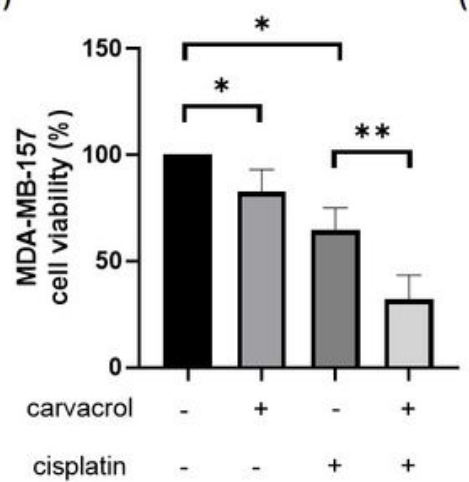

(C)

(E)

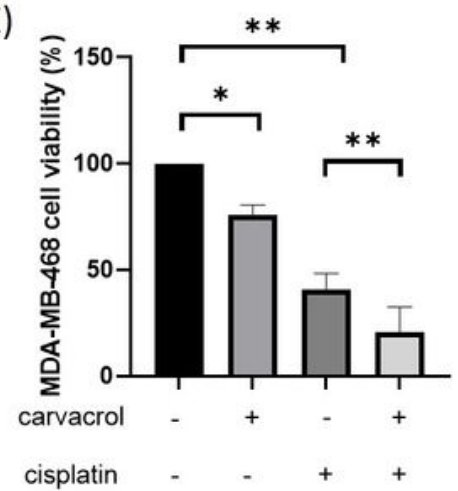

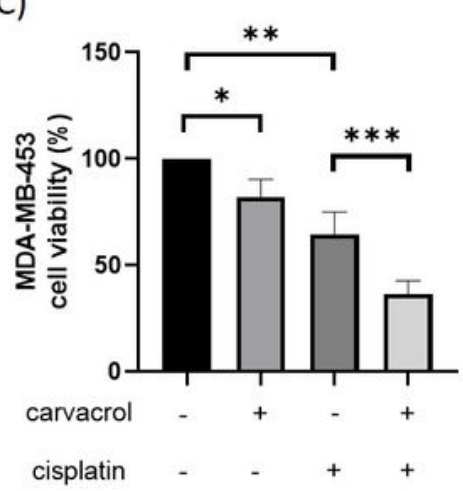

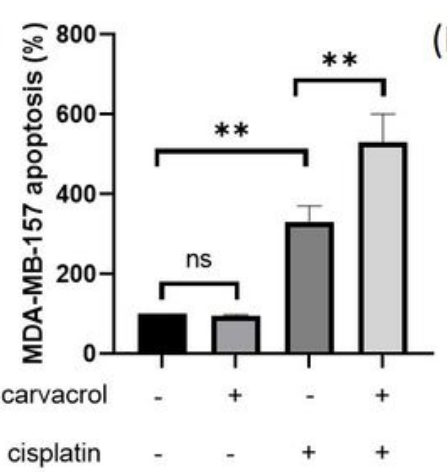

(H)

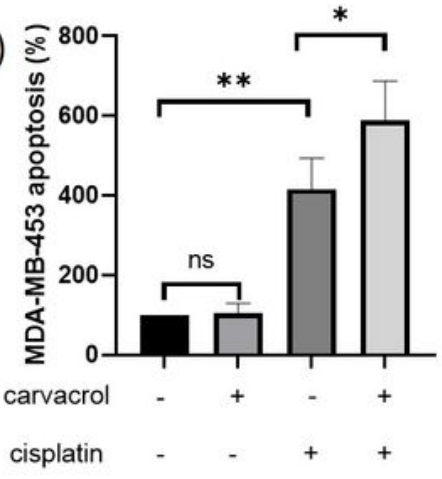

(J)

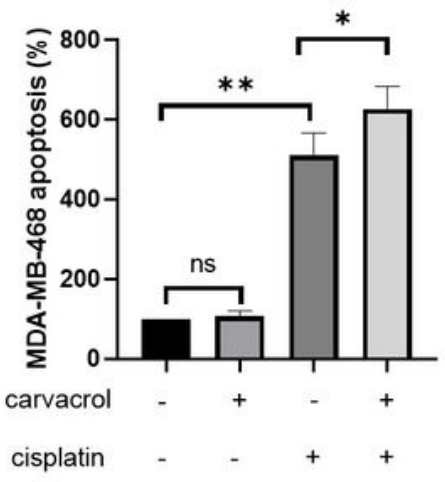

Figure 2

Effect of carvacrol and cisplatin on cell viability and apoptosis of TNBC cell lines. A-E. Effect of carvacrol and cisplatin on cell viability and apoptosis of TNBC cell lines The cells were exposed to test drugs for 48 hours and the viability was determined using MTT assay. F-J. Effect of carvacrol and cisplatin on cell apoptosis of TNBC cell lines. The cells were exposed to test drugs for 48 hours and the apoptosis was 
determined using Bax ELISA. Statistical significance was analyzed using a Student's unpaired t-test (NS = $\mathrm{P}>0.05, *=\mathrm{P}<0.05, * *=\mathrm{P}<0.01, * * *=\mathrm{P}<0.001)$.

(A)

4T1 implanted in the mammary fat pad

Administration of Cisplatin every three days

Administration of Carvacrol everyday

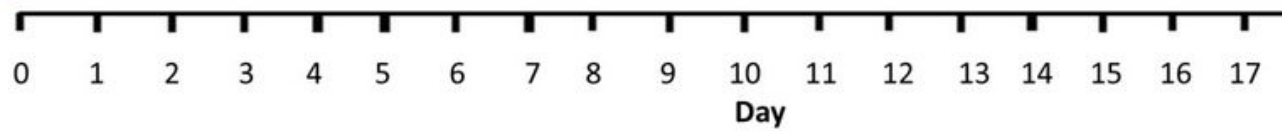

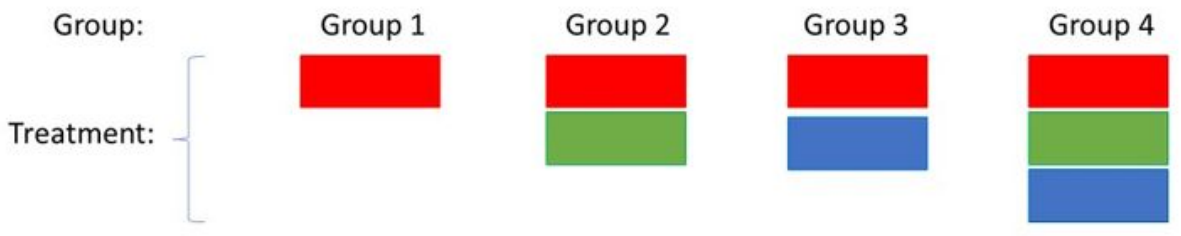

(B)

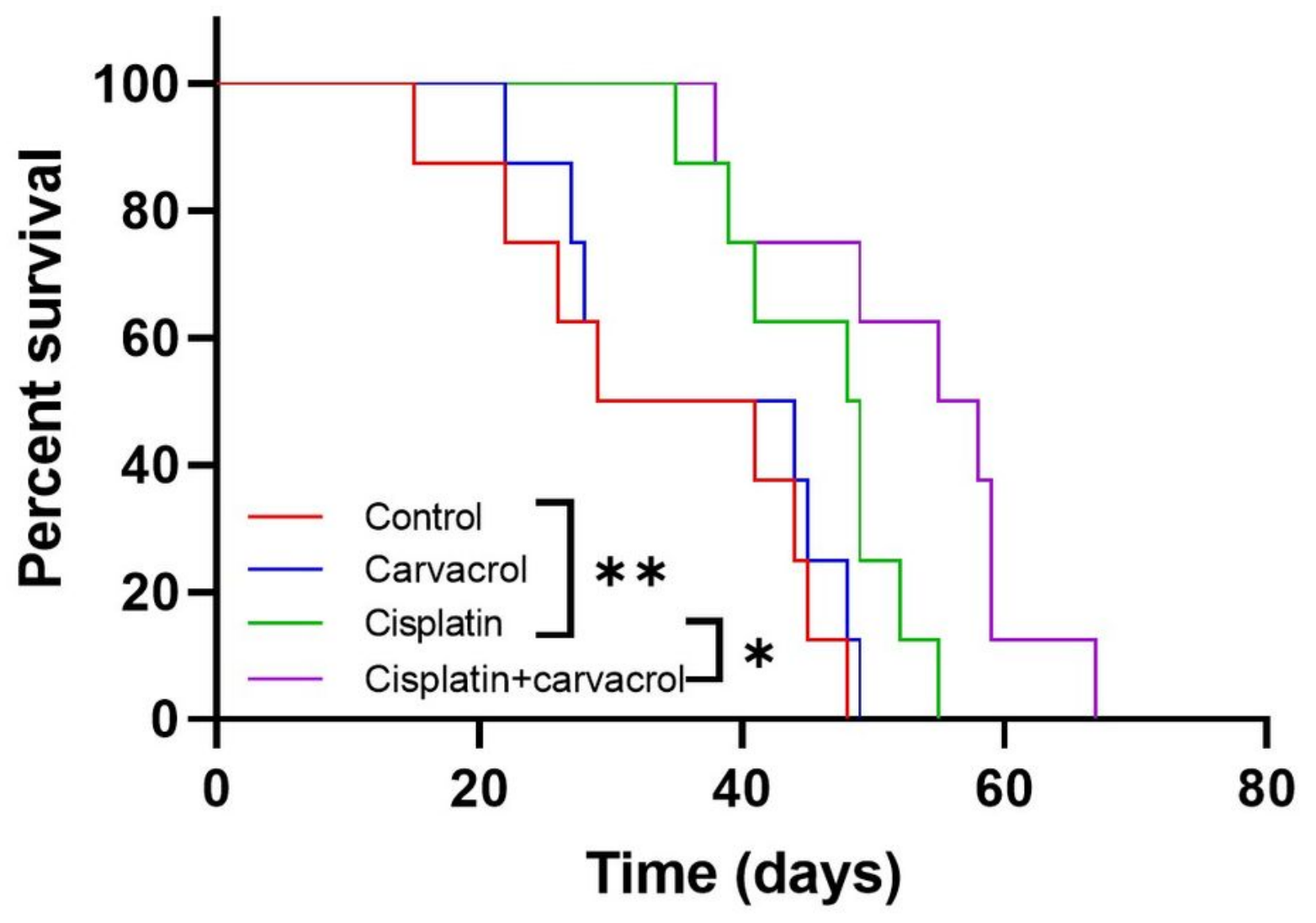

Figure 3

Effect of carvacrol on cisplatin-mediated survival improvement of an orthotopic murine breast cancer model. (A) Schematic diagram of the experimental design. Briefly, 4T1 cells were injected in the mammary fat pad of female mice to induce breast cancer. The mice were allocated to four groups 
according to their body weight. 4 groups ( $\mathrm{n}=8$ ) were injected intraperitoneally with the vehicle, $3 \mathrm{mg} / \mathrm{kg}$ cisplatin, $200 \mathrm{mg} / \mathrm{kg}$ carvacrol, and $3 \mathrm{mg} / \mathrm{kg}$ cisplatin $+200 \mathrm{mg} / \mathrm{kg}$ carvacrol respectively. The animals were fed until the death of the animals and the survival data of all animals was recorded. (B) Survival data of the animals. $\left({ }^{*}=P<0.05,{ }^{*}=P<0.01\right)$.

(A) $4 \mathrm{~T} 1$ implanted in the mammary fat pad
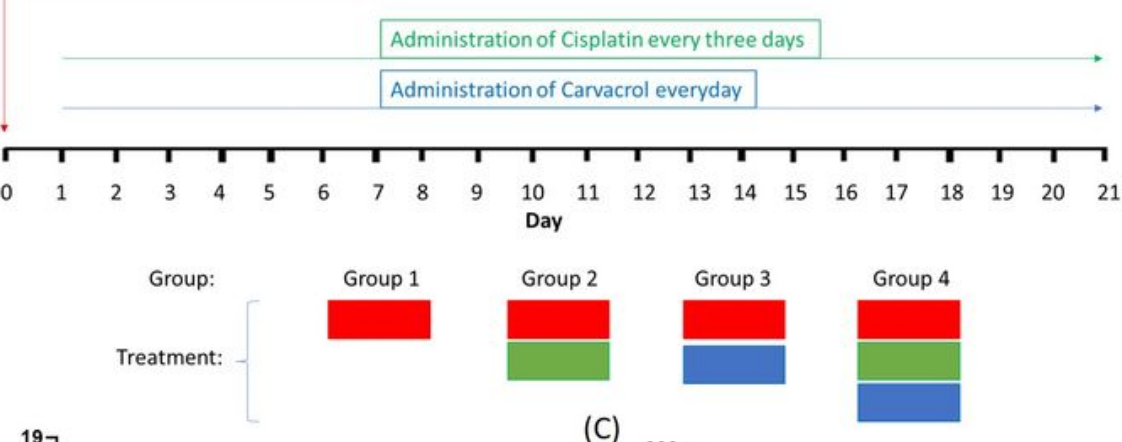

(B)

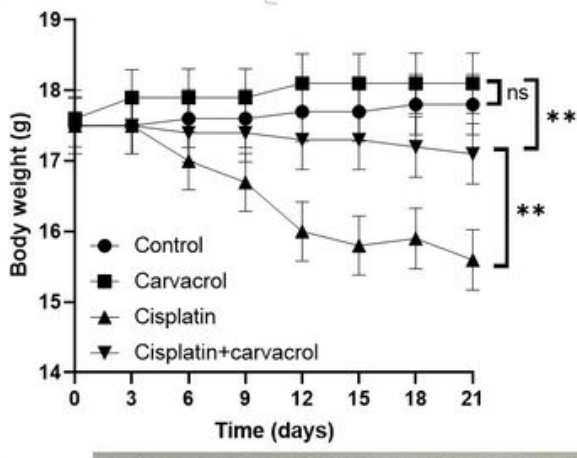

(D)

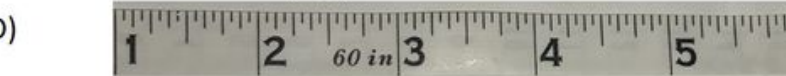

(F)

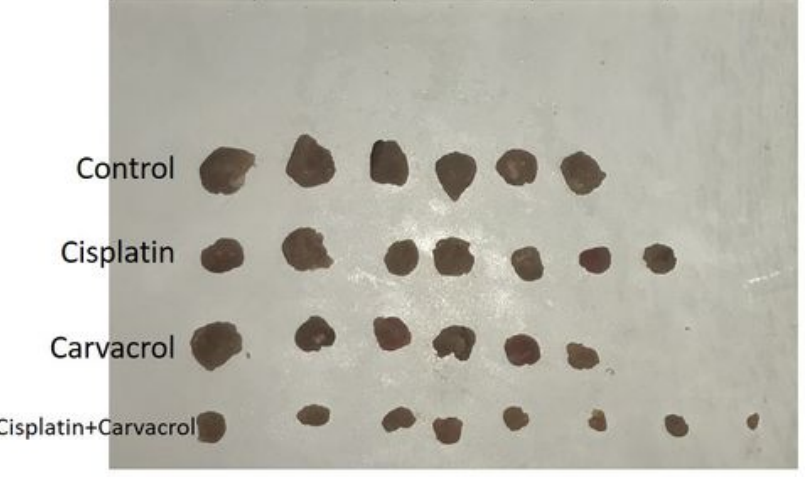

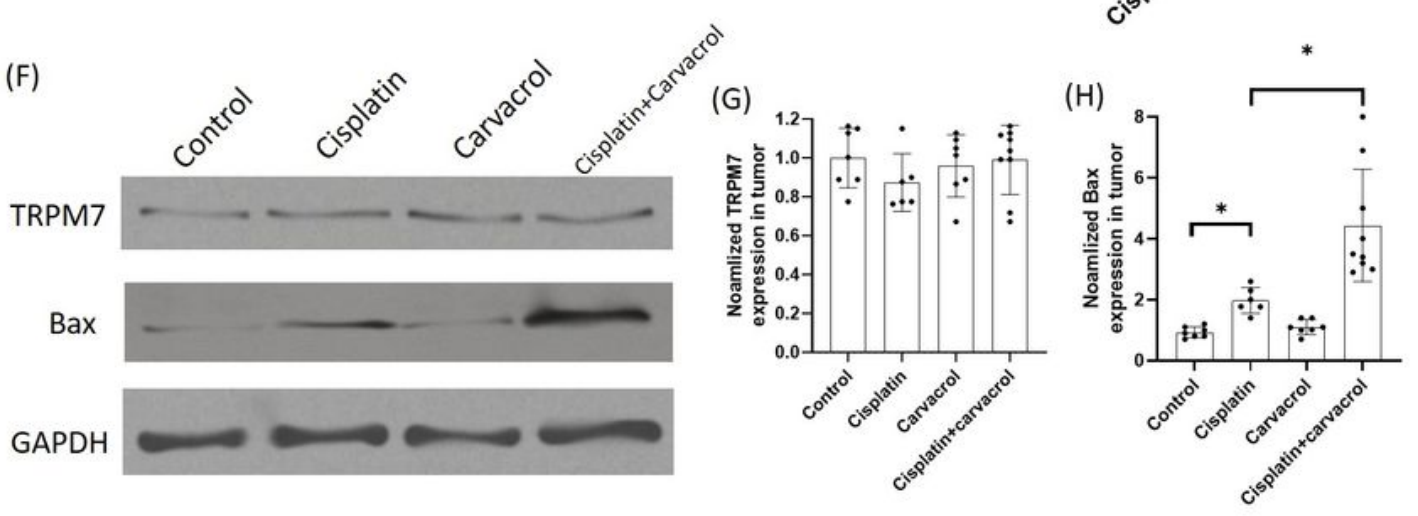

(C)

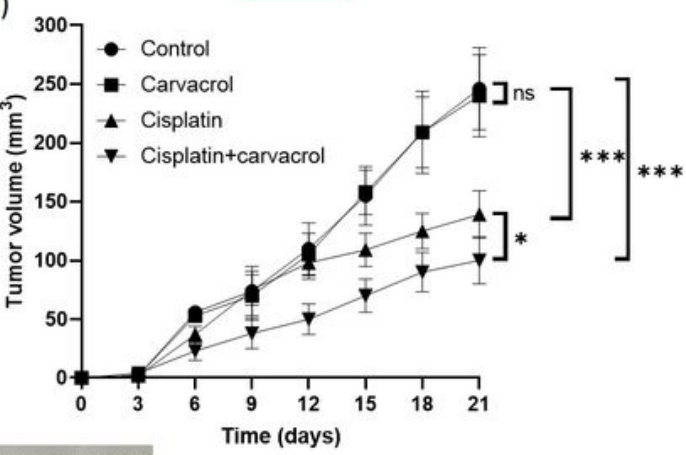

(E)

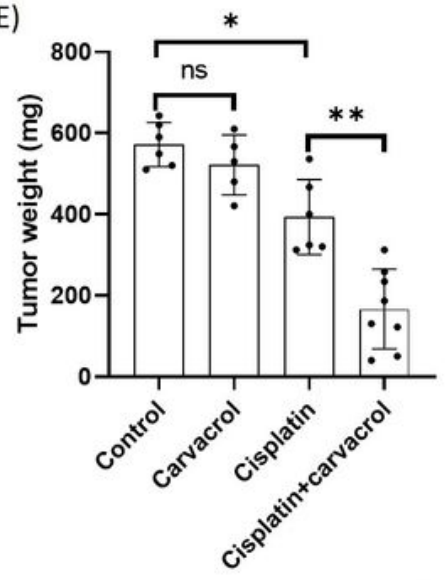

Figure 4 
Effect of carvacrol on cisplatin-mediated suppression of breast cancer development in an orthotopic murine breast cancer model. (A) Schematic diagram of the experimental design. Briefly, 4T1 cells were injected in the mammary fat pad of female mice to induce breast cancer. The mice were allocated to four groups according to their body weight. 4 groups were injected intraperitoneally with vehicle $(n=6), 3$ $\mathrm{mg} / \mathrm{kg}$ cisplatin $(\mathrm{n}=7), 200 \mathrm{mg} / \mathrm{kg}$ carvacrol $(\mathrm{n}=6)$, and $3 \mathrm{mg} / \mathrm{kg}$ cisplatin $+200 \mathrm{mg} / \mathrm{kg}$ carvacrol $(\mathrm{n}=8)$ respectively. The body weight and tumor volume were measured every three days. All the animals were euthanized at the endpoint of the experiment (day 21) and the net tumor weight was measured. Data of animals that died before the endpoint of the experiment were excluded. (B) Body weight. (C) Tumor volume. (D) Image of tumors. (E) Tumor weight. (F) representative image of western blotting analysis. The tumor samples were used to extract proteins followed by western blotting assay with TRPM7 and Bax antibodies. (G) Normalized TRPM7 protein expression in tumor samples. $(\mathrm{H})$ Normalized Bax expression in tumor samples. Statistical significance at the endpoint was analyzed using a Student's unpaired t-test $\left(\mathrm{NS}=\mathrm{P}>0.05,{ }^{*}=\mathrm{P}<0.05,{ }^{*}=\mathrm{P}<0.01, * * *=\mathrm{P}<0.001\right)$.

(A)

$\operatorname{Mix}\left\{\begin{array}{cccccccc}\text { TRPM7 siRNA(nM) } & 0 & 0.5 & 1 & 2 & 4 & 10 & 20 \\ \text { Negative siRNA(nM) } & 20 & 19.5 & 19 & 18 & 16 & 10 & 0\end{array}\right.$

(B)

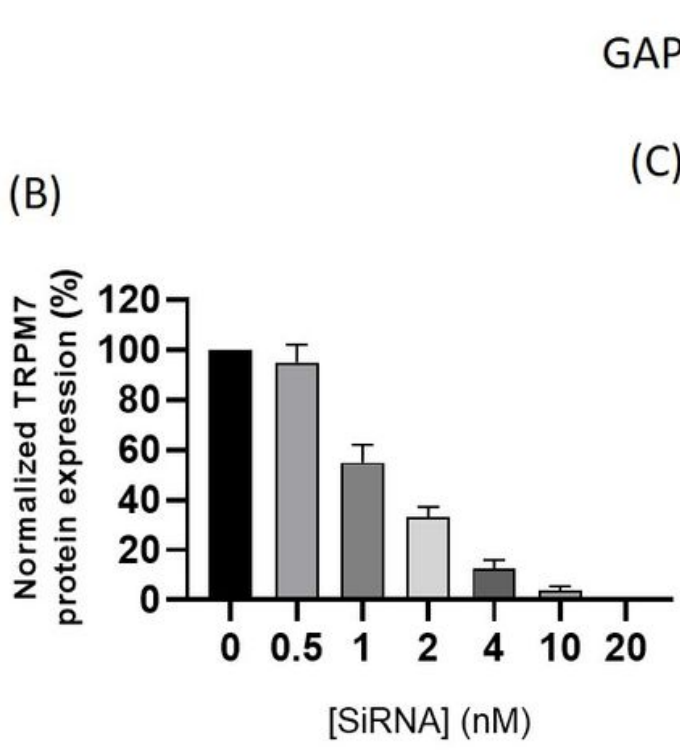

TRPM7

(C)

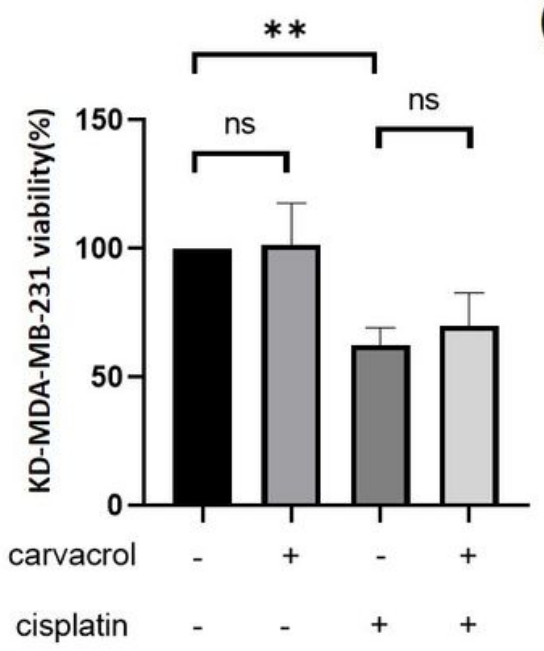

(D)

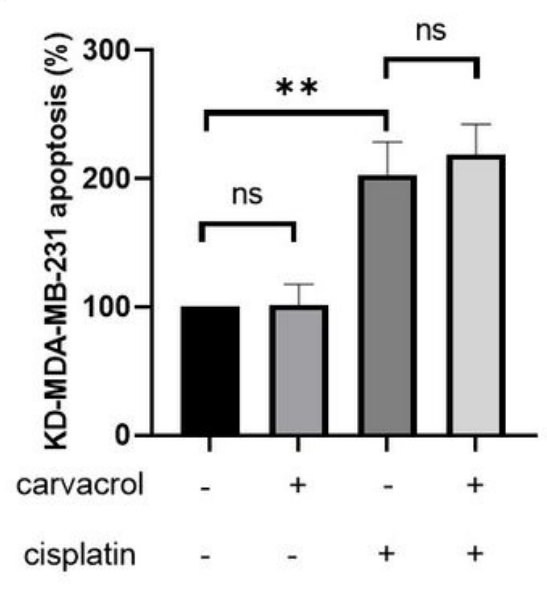

\section{Figure 5}

TRPM7 knockdown in MDA-MB-231. (A) A representative image of western blotting assau in TRPM7 knockdown experiment. Different concentration of TRPM7 siRNA (mix with negative siRNA) was transfected into MDA-MB-231. After 48 hours, the cells were harvested and Western blotting was used to analyzed the TRPM7 expression in cells. (B) TRPM7 expression after the transfection. (C) Effect of carvacrol and cisplatin on cell viability of TRPM7 knockdown MDA-MB-231. The cell viability was 
determined using MTT assay. (D) Effect of carvacrol and cisplatin on cell apoptosis of TRPM7 knockdown MDA-MB-231. The cell apoptosis was determined using Bax ELISA. Statistical significance was analyzed using a Student's unpaired t-test (NS $=\mathrm{P}>0.05,{ }^{*}=\mathrm{P}<0.05, * *=\mathrm{P}<0.01$, $* \star *=\mathrm{P}<0.001$ ).
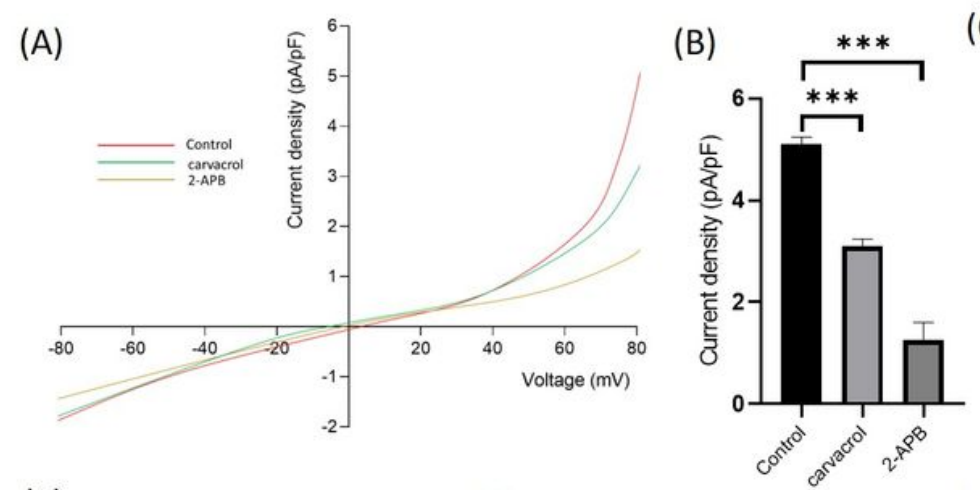

(E)

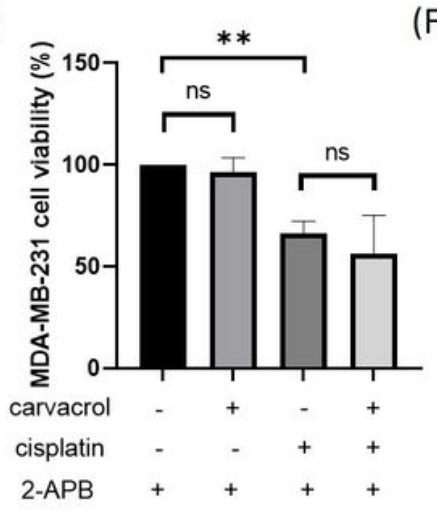

(F)

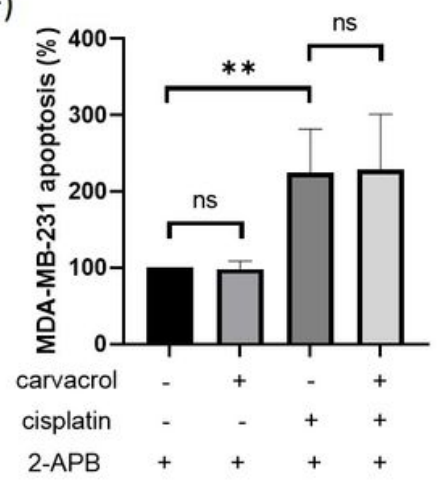

(C)

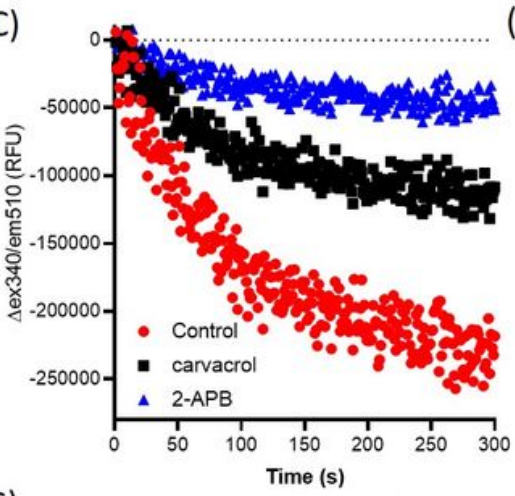

(D)

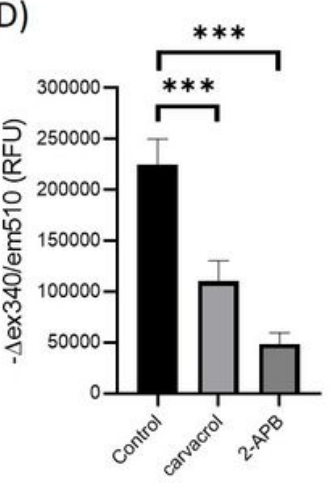

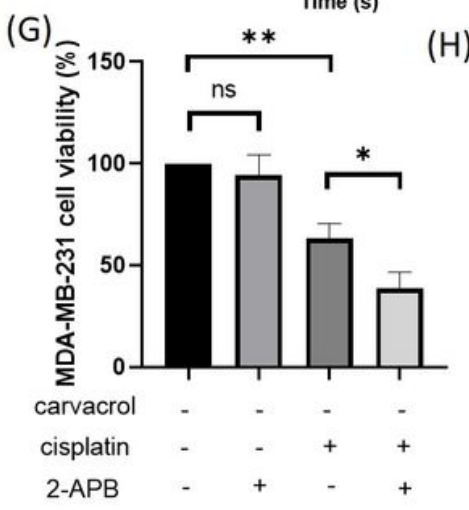

(H)

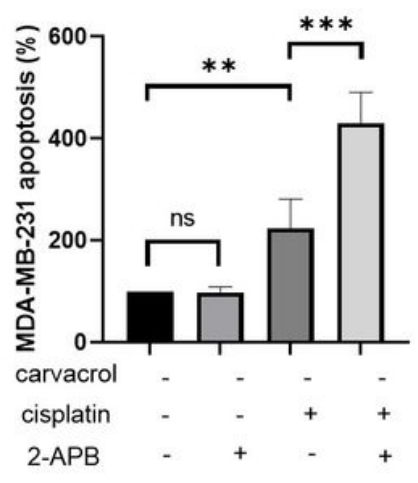

Figure 6

Effect of TRPM7 inhibitor 2-APB on carvacrol/cisplatin suppression. (A) Representative TRPM7-like currents in MDA-MB-231. Patch-clamp was used to measure the TRPM7-like currents in transfected MDAMB-231. (B) TRPM7-like current density in MDA-MB-231. (C) TRPM7-mediated fluorescence quenching data in MDA-MB-231. Fura-2AM-based quench assay was used to measure TRPM7-mediated influx in MDA-MB-231. (D) Fluorescence quench amount at the last $5 \mathrm{~s}$ in Fura-2AM-based quench assay. (E) Effect of 2-APB on carvacrol/cisplatin viability suppression. (F) Effect of 2-APB on carvacrol/cisplatin apoptosis suppression. (G) Effect of 2-APB on cisplatin viability suppression. (H) Effect of 2-APB on cisplatin apoptosis suppression. The cell viability and apoptosis were determined using MTT and Bax ELISA respectively. Statistical significance was analyzed using a Student's unpaired t-test (NS $=P>0.05$, $*=\mathrm{P}<0.05, * \star=\mathrm{P}<0.01, * \star \star=\mathrm{P}<0.001)$. 